\title{
Simultaneous interpreting as an aid in parallel-medium tertiary education
}

\author{
Marné Pienaar \\ Dept. of Linguistics and Literary Theory, University of Johannesburg, \\ Auckland Park Campus, P.O. Box 524, Auckland Park 2000. E-mail: mpi@lw.rau.ac.za
}

\section{Introduction}

In South Africa, the language policies of tertiary educational institutions have been a point of serious concern and debate over the past number of years (see De Klerk 2001:27-32; Dlamini 2001:33-40; Johl 2001:5-8; Pienaar 2001:41-47; Roodt 2001:1520; Smit 2001:21-26; Van Rensburg 2001:9-14). Historically, Afrikaans-medium universities, especially, have been affected by pressure to re-evaluate their policies and to provide teaching in English.

It must however be stated that more than politics had a role to play. South African universities also have to be pragmatic. For the former Rand Afrikaans University (RAU), now the University of Johannesburg, that meant acknowledging that the Afrikaans market was not big enough to justify the existence of yet another Afrikaansonly university. Consequently, parallel-medium teaching was introduced in 1998, whereby all undergraduate classes were to be presented twice, once in English and once in Afrikaans. This duplication of classes, however, did not take place without hindrances. The seemingly most obvious stumbling block - that of the level of English language proficiency of predominantly Afrikaans-speaking lecturers - proved to be least problematic. The impact of duplication and the subsequent increased lecturing load were clear from the decrease in research output. Yet, in strictly economic terms, 
duplication worked and RAU student numbers increased dramatically. Already by 2002, students in the English-medium classes significantly out-numbered their counterparts in the Afrikaans-medium classes. By 2004, the enrollment figures pointed to a 4:1 ratio of English to Afrikaans.

Apart from having to provide services to translate written material such as study guides, test and examination papers, new challenges emerged with regard to the appointment of lecturers who were not proficient in both languages, in this instance, specifically in Afrikaans. Tough decisions had to be made when considering whether to appoint a lesser qualified candidate who was proficient in both languages or to appoint a stronger candidate who was not able to lecture in Afrikaans. If the last option was followed, or if no candidates who were comfortable with lecturing in Afrikaans had applied and a nonAfrikaans-speaking person had subsequently been appointed, the impact of the required language policy was deeply felt within departments. It generally meant that such a person might end up with a lighter lecturing load than the other lecturers in the department and that his or her lectures then had to be duplicated in Afrikaans by someone else for whom the specific field might not be an area of preference or specialisation.

It was further noted that Afrikaans-speaking students were marginalised, in the sense that they did not have the benefit of access to the knowledge base of senior lecturers who could not teach them in Afrikaans. It was against this background that it was decided to experiment with simultaneous interpreting as a possible means of closing the language gap between English-speaking academic experts and Afrikaans-speaking students. This paper reports on the findings of this experiment, after distinguishing between various kinds of interpreting.

\section{Interpreting}

Pöchhacker and Schlesinger (2002:2,3) state that "interpreting can be defined most broadly as interlingual, intercultural oral or signed mediation, enabling communication between individuals or groups who do not share, or do not choose to use [emphasis mine], the same language(s)". 
Generally, a distinction is drawn between liaison interpreting and conference interpreting, where "liaison interpreting" would refer to "situations in which bidirectional interpreting is required by two or more parties to a conversation who do not understand each other's language and would thus be unable to communicate without the assistance of an interpreter" (Erasmus 1999:viii). Typically, liaison interpreting would be associated with interpreting by the children of immigrants, hospital cleaners, tour guides or any trained or untrained persons who find themselves in the role of language facilitator. The term "conference interpreting", on the other hand, is used to refer to interpreting which takes place at national or international conferences or symposia and is associated with highly trained interpreters.

In the past, two modi of interpreting were distinguished, namely simultaneous interpreting and consecutive interpreting. In liaison interpreting, the consecutive mode is mostly used, whereas conference interpreters would use either the simultaneous or the consecutive mode. Simultaneous interpreting provides for the (almost) simultaneous rendering of a message in a language other than that which is used by the speaker. In contrast to consecutive interpreting, simultaneous interpreting allows for uninterrupted speech and a lower level of summary than where interpreters have to take notes, for instance, and are only given the opportunity to interpret after the speaker has completed his/her speech. Provided that the interpreter has prior access to documentation, that the speaker accommodates the interpreter and that no technical problems occur, the simultaneous mode of interpreting could potentially bridge a language gap effectively.

A further distinction should be made between simultaneous interpreting where portable equipment and the whispering mode are used and conventional simultaneous interpreting where interpreters sit in interpreting booths. The advantage of the first lies in the fact that the service is mobile and the possibility of technical problems is lessened. A definite disadvantage is the fact that audibility can be a problem, as the interpreter cannot rely on headsets and volume control to improve the audio quality of the input. It has also been recorded that some interpreters felt more "vulnerable" without the glass shield that is provided by the booth. ${ }^{1}$ The possibility for partner assistance is also lessened, as interpreters feel that pressing the mute button and asking for help is more obvious when they are not seated in a booth. This is understandable if it is kept in mind that interpreting booths are generally placed at the back or at the side of venues, 
whereas the interpreter who works in whispering mode making use of portable equipment often has to adjust his/her position in the venue to be closer to the current speaker in an attempt to hear the speaker better. However, in small meetings, the whispering mode can be very effective, although interpreters do find it more straining than working in a booth.

\section{Simultaneous interpreting as an aid in parallel-medium tertiary education}

The use of simultaneous interpreting in the whispering mode to facilitate teaching appears to be a new field of study, and apart from Van Rooy (2005) and the research reported below, literature related to this field is still largely unavailable. At first glance, one might assume this form of interpreting to be similar to conference interpreting. However, the findings below seem to indicate that the level of mediation experienced by the interpreters necessitates a change of view: educational interpreting should rather be seen as a form of liaison interpreting.

In this section, two cases of the use of simultaneous interpreting to facilitate teaching at tertiary institutions are presented. Firstly, the case of the Potchefstroom campus of the North-West University is briefly discussed. Secondly, the case of the former RAU is covered in more detail.

\subsection{The Potchefstroom experience}

During 2004, the Potchefstroom campus of the North-West University implemented the use of simultaneous interpreting into English in selected classes. Unlike RAU, the Potchefstroom campus does not offer parallel-medium teaching but uses Afrikaans as medium of instruction. According to Mr Johan Blaauw, particularly those students who spoke an African language as first language could perceive that they were disadvantaged by the University's language policy. An experiment was subsequently conducted to establish if such students would benefit from English-medium tuition - be it by means of simultaneous interpreting or by the direct use of English as medium of instruction. At the same time, the experiment also sought to establish if Afrikaansspeaking students would be disadvantaged by the use of English as medium of instruction. Van Rooy (2005:86) reports as follows: "As far as the straight-forward comparisons between Afrikaans and English as media of instruction are concerned, it is clear that Afrikaans learners perform much better in Afrikaans classes than in English 
classes, while Black learners perform much better in English classes than in Afrikaans classes". Based on the results, it was recommended that simultaneous interpreting from Afrikaans into English be implemented at the Potchefstroom campus; that Afrikaans be used as medium of instruction for Afrikaans-speaking students, and that further research be undertaken into the feasibility of rendering a simultaneous interpreting service from English into Afrikaans. ${ }^{2}$ However, it should be borne in mind that the student body at the Potchefstroom campus differs significantly from that of the former RAU. The majority of students at Potchefstroom is Afrikaans-speaking. In contrast, as stated earlier, at RAU, students who preferred English as medium of tuition (first and second language speakers) outnumbered Afrikaans-speaking students by approximately 4:1 by 2004.

\subsection{RAU case study}

In 2003, RAU started to make use of simultaneous interpreting at its board meetings. This was primarily done to make it possible for board members who did not understand Afrikaans to follow the proceedings, but also to allow Afrikaans-speaking members to express their views in their language of choice. However, the cost of hiring equipment led to the decision to invest in portable equipment. The response to the availability of the portable equipment was enormous and, with the increasing number of non-mothertongue speakers of Afrikaans appointed at RAU, it was decided early in 2004 to expand the service to senate meetings, faculty board meetings and the institutional forum. A second set of equipment was obtained to keep up with the demand for interpreting services. The heightened visibility of the interpreting service subsequently led to a request to interpret a series of lectures where the lecturer was an esteemed academic who could not duplicate his lectures in Afrikaans. Instead of depriving students of the opportunity to benefit from the knowledge base of the lecturer, it was decided to interpret this particular series of lectures on second year level in Development Studies into Afrikaans. Because the class was small (consisting of 10 students only), it was envisaged that the whispering mode should not lead to much disruption, as it was unlikely that the interpreter would have the need to move around. Furthermore, the Head of Department, Prof. Thea de Wet, expressed concern about the homogeneous nature of the students in the Afrikaans class. In her opinion, the English class was more heterogeneous in student make-up and debate in the English class was much more stimulating, as students came from very diverse backgrounds and held divergent points 
of view. According to her, this was lacking in the Afrikaans class, and one of the reasons why she was interested to see if simultaneous interpreting could result in an integrated class situation without compromising the University's language policy.

\subsubsection{Research question}

The main research question was whether simultaneous interpreting making use of the whispering mode could be used as an aid in parallel teaching. This question is of particularly importance if one bears in mind that the students for whom the interpreting was intended are second language speakers of English and could therefore, in theory, follow English. However, the University pursues a policy of parallel-medium teaching which guarantees undergraduate students the option of attending classes in either English or Afrikaans, and these students have opted for the Afrikaans class, thereby indicating a preference for this medium of instruction. The lecturer, Dr Peter UbomboJaswa of Uganda, who does not speak or understand Afrikaans, was aware of the fact that the students understood English, but he was willing to partake in the experiment. Unlike situations where the interpreter acts as mediator between two groups who do not share the same language, this was therefore a clear case of mediating between two groups who chose to use two different languages (see definition of "interpreting" in Section 2). Although the advantages of providing simultaneous interpreting were clear, namely providing students with access to the knowledge base of an academic expert while at the same time allowing both the students and the lecturer to use their respective languages of preference, the question still remained as to whether the students would make use of the service, given the fact that they understood English. Also, the researcher wanted to establish if there were certain circumstances under which the students would or would not use the service.

\subsubsection{Methodology}

Three interpreters were used who alternated weekly. They were all mother-tongue speakers of Afrikaans and experienced university lecturers. All three had worked as interpreters in the Gauteng Legislature and were therefore to a certain extent familiar with the field of Development Studies.

As the interpreters, lecturer and Head of Department were hesitant to create a perception of "language as a problem" with respect to the Afrikaans students, it was decided that 
the Head of Department would introduce the interpreting system to the students with as little fuss as possible. At the start of the first class, she introduced both the lecturer and the interpreter to the students and explained that an interpreting service would be made available in Afrikaans. The interpreters sat at the back of the class (a relatively small venue) in an attempt to draw as little attention as possible. At no point were the students asked whether they needed the service.

\subsubsection{Results and discussion}

\subsubsection{The students}

During the first class, only one student did not make use of the equipment, whereas all the others kept on the equipment for the duration on the class. After the class, the first of three feedback sessions was held during which the students indicated the following:

(i) The quality of the interpreting was very good.

(ii) They had to look down to concentrate on the interpreting, because looking at the lecturer affected their focus on the incoming message.

(iii) When questions were asked, the lag-time caused some inconvenience as they would only realise a question was asked a few seconds after their classmate who was not using the interpreting equipment. (This was indeed evident from the fact that, whenever a question was asked, the student who did not use the equipment had her hand up to answer a moment or two before the rest.)

(iv) They supported the concept of interpretation, but stated that, as they all perceived themselves as proficient in English, the reason why the classes were interpreted was not clear to them. One student observed that if the lecturer used his mother-tongue (Swahili) such a service would clearly be mandatory. (This is an interesting point as classes are duplicated and the students have the option of attending the English class. The fact that they opted for the Afrikaans class does therefore indicate a preference for Afrikaans.)

Judging by her English responses, the student who opted not to make use of the equipment was not that proficient in English. During the feedback session, she also switched to English when she realised the lecturer was not following. Only after it had been explained to her that the feedback would be translated for the lecturer, did she switch back to Afrikaans. From this it becomes clear that more than language proficiency has a role to play - attitude and awareness of others, social sensitivity, etc. 
play important roles when deciding to make use of interpreting services in this specific context.

During the second class, the same pattern was followed, with all but one student making use of the service. Students also brought along friends to listen to the interpreting service, amongst whom was a reporter for the campus newspaper KampusBeeld who wanted to interview the interpreter. The immense hegemony of English was evident from one of the questions she asked, namely whether students would not loose their ability to speak English if interpreting was available in all instances!

A second feedback session was held before the third lecture commenced. By then the students seemed to have accepted the service and indicated that they would continue making use of it. However, they indicated that the headsets became uncomfortable after an hour and mentioned that they would take it off for short periods during the last 30 minutes of the lecture.

In the course of the next four classes, less students made use of the equipment. When the final lecture was due, the interpreter was informed that the students would be writing a test for the first hour and that interpreting would only be needed for the second part of the class. When the interpreter arrived, the test had been written and the lecturer had started to explain the examination format to the students (in English). The interpreter asked the students if they needed interpreting. This was the first time that the question was posed to them; up until then, the headsets were merely handed out. It was clear that the students felt uncomfortable, as they were in fact listening to the lecturer in English when the interpreter arrived. Two students raised their hands in response to the interpreter's question, but when the rest of the class indicated that they did not need the headsets, these two also declined.

This apparent unwillingness to make use of an interpreting service comes as no surprise and tallies with other findings (see Pienaar 2002:274). Wallmach (2004:8) also observed a certain hesitance with delegates who attended a conference to make use of the interpreting service: 
In a country like South Africa, interpreters do tend to play an active role in conference interpreting, since there is often a clear gap in status and education between speakers and audience, a situation which in developed countries is far more common in liaison interpreting contexts. The interpreter must fill that gap by playing an advocacy role, making complex concepts accessible, 'seizing the surge of language'. Because the elite speak English, and it is the less educated who need interpreting, delegates who make use of interpreting services can be looked down upon. At the national conference of the ruling party a few years ago, attended by over 3000 delegates, the interpreting headsets were rather shockingly described as "hearing aids" by the chairperson, who pleaded with "those who need these hearing aids not to take them out of the conference venue as they are not remote controls or radios, and cannot be used to replay Mandela's speech in your room later on!" I have found that the best way to ensure that people make use of interpreting services is to hand out headsets personally, and also to explain to the delegates that they will be serving the interests of multilingualism if they provide the hard-working interpreters with feedback. In this way, the stigma of using the headsets (and being unable to speak English) is lessened.

\subsubsection{The lecturer}

In the lecturer's opinion, the interpreting service worked well. He indicated that he would like to see it extended to other courses in his department. During the second lecture, he informed the students that the interpreting service was an experiment and said that, if successful, it could be implemented in the sense that lectures would be done in English only, the two language groups integrated and interpreting provided (into Afrikaans).

The lecturer did not experience the service as a hindrance and, even though the venue was small, he did not find the whispering an obtrusion. When the interpreter spoke to the lecturer after the last lecture when the students indicated they did not need the service, he agreed that it was a mistake to ask students whether they needed the service, as the students did have a working knowledge of English and the hegemony of English was so strong that one could not be seen as having difficulties with it. In spite of the fact 
that the students declined the service when it was offered, the lecturer said he noted some of the students struggling without the interpreting.

\subsubsection{The interpreters}

Apart from "normal" interpreting issues, such as audibility, the interpreters stated that they had very little trouble interpreting the course. During the first class, notes were handed to the students but not to the interpreters. Not wanting to draw attention, they decided to make do without them. After the class, the interpreters explained to the lecturer that they should always be provided with whatever notes were to be handed out, and the lecturer subsequently obliged.

However, all three interpreters noted they were aware of the fact that they mediated to a larger extent than what they would have in other contexts by, for instance, repeating things the lecturer had emphasised. The fact that all interpreters are university lecturers might partially explain this. However, it is more likely that this particular setting and mode are more closely linked to liaison interpreting than originally envisaged.

\section{Educational interpreting as a form of liaison interpreting}

In her discussion on definitions of "interpreting", Roy (2002:347) points out that "most of the descriptions of interpreting concentrate on a clarification or explanation of the role of the interpreter". She mentions that professional interpreters often describe their role as being in the middle by using a metaphor which states that they serve as a kind of channel or bridge through which communication between people takes place. In this sense, the role of interpreters has been compared to a machine, a window, a bridge and a telephone. The role of the interpreter, however, entails more than merely processing information back and forth. According to Roy (2002:348), the interpreter requires knowledge of organised systems, grammatical and discourse systems, language use systems, as well as emergent adaptive systems to perform their task successfully and consistently.

Historically, interpreters were often viewed as helpers, and as such they were free to offer advice, translate and make decisions for one or both sides. The change in expectations consumers had, as well as the profession's own need to see itself as rendering professional services, led to the conduit model where the interpreter was 
equated to a machine. This made it possible for interpreters to detach themselves from any decision-making responsibilities. The resulting impartiality to this day remains central to the Code of Ethics adopted by interpreting associations. However, this impartially often leads to clients feeling that interpreters were cold and distant and did not really take interest in their task. Subsequently, a new image was found to explain the role of the interpreter, namely that of communication facilitator. During the late 1970's and the early 1980's, it was largely agreed that interpreters should be sensitive to the fact that they do not only communicate across languages but also across cultures, and the idea of 'the interpreter as a bilingual, bicultural specialist' was foregrounded (Roy 2002:349-351).

Although the conduit model seems to persist, practising interpreters are all too aware of the fact that, depending on the situation, their function entails more than mere language transfer. This is particularly true in liaison interpreting, where the advocacy model, for instance, is often still promoted (see Drennen 1999:118).

Although the role of the interpreter is difficult to define, Roy (2002:252) states that "the interpreter is an active, third participant with the potential to both influence the direction and the outcome of the event, and ... the event itself is intercultural and interpersonal rather than mechanical and technical".

This active participatory role also seems to apply to simultaneous interpreting in parallel-medium tertiary institution's classrooms. This is partially due to the nature of the equipment. Compare Kim Wallmach's comment: "As a conference interpreter one is used to being separated from the audience, but when using whispered sim equipment, you in fact become a liaison interpreter rather than a conference interpreter, with all the conditions of liaison interpreting - face-to-face contact, role conflict etc" (interpreters@topica.co.za).

Anderson and Bruce's (2002:210) discussion on the roles of the interpreter brings another perspective. He makes the point that there seems to be a difference in the level of identification interpreters have with clients for whom they have to interpret into their (the interpreters') dominant language and those for whom they have to interpret into their other language, in the sense that the level of identification is far stronger when the 
dominant language is used. When this hypothesis was tested on the interpreters who participated in the case study, they all agreed that they "felt sorry" for the students. It was also noted that the lecturer asked the interpreters to help with the translation of study guides, and one of the interpreters said she found it extremely difficult to refrain from offering to translate notes to help the students (although it clearly was not part of her job description). However, it is unlikely that the level of identification can only be ascribed to the fact that the interpreters worked into their dominant language.

\section{Conclusion}

From the above, it is clear that simultaneous interpreting is an option that can be used to facilitate teaching in parallel-medium tertiary education. However, the use of portable equipment, as well as the setting itself, led to a situation where one cannot simply equate the interpreting done here with conference interpreting. Rather, educational interpreting has closer links with liaison interpreting than with conference interpreting.

Although there is technically-speaking no reason why simultaneous interpreting cannot be used as an alternative to the duplication of classes, the RAU case study does seem to indicate that the hegemony of English could stand in the way of a fully fledged interpreting service.

If the reasons for the experiment cited above be reconsidered (namely the University's language policy, the inability of certain academic staff to teach in Afrikaans, as well as the view of some staff members that the homogenous nature of the Afrikaans classes hampers class discussion), it might be a solution not to limit interpreting to Afrikaans classes only, but to do away with parallel-medium instruction and rather introduce a system whereby lecturers use their language of preference coupled with interpretation into the other language. This will allow students the benefit of the knowledge base of the lecturer; the lecturer will have the benefit of speaking his/her language of preference; students should benefit from using their language of preference; and multiculturalism will be enhanced, as making use of the interpreting equipment will not be restricted to one group only. If this is not feasible, the hegemony of English must at the very least be taken into consideration in the way in which the use of simultaneous interpreting is marketed or presented to users. 


\section{Notes}

1. Compare an interpreter's comment on the use of portable equipment and the whispering mode: "I worked once with the sim equipment but I must confess that I wasn't too convinced. It's better than plain 'manual' whispering, but I felt vulnerable without the protection of the booth, I could hear the external sounds in and outside the room (coughing, the cars outside, etc), one has to hold the microphone in the hand... I couldn't concentrate properly. I wouldn't accept another job like that in a hurry" (interpreters@topica.co.za).

2. The Northwest University has since extended its interpreting programme, and the results are promising: in 2005, 75\% of the students in Physics that had access to the interpreting service passed, whereas only $35 \%$ of the group who had no access to the service passed (Beeld, 27 October 2005). However, it must be stressed that interpreting at the Northwest University is done into English, whereas, in the case of the former RAU, interpreting was done into Afrikaans. 


\section{References}

Anderson, R. and W. Bruce. 2002. Perspective on the role of the interpreter. In F. Pöchhacker and M. Schlesinger (eds.) The interpreting studies reader. London and New York: Routledge. pp. 210-217.

Beeld, Thursday 27 October 2005, 'Tolke in die klas'.

De Klerk, V. 2001. From the sublime to the ridiculous - or somewhere in between? A language policy for an historically English medium university. Aambeeld/Anvil 29(1): 27-32.

Dlamini, C.R.M. 2001. The attainability of multilingualism at universities. Aambeeld/Anvil 29(1): 33- 36.

Drennen, G. 1999. Organisational factors affecting the provision of language services in mental health care. In M. Erasmus (eds.) Liaison interpreting in the community. Pretoria: Van Schaik. pp. 109-122.

Erasmus, M. (eds.) 1999. Liaison interpreting in the community. Pretoria: Van Schaik. interpreters@topica.co.za (accessed on 1 July 2004).

Johl, C.S. (eds.) 2001. Die taal van universiteite in Suid-Afrika. Aambeeld/Anvil 29(1): 5-8.

Pienaar, M. 2001. Op pad na veeltaligheid: uitdagings op grondvlak, die waarde en beperkinge van 'n taaloudit, belowende inisiatiewe. Aambeeld/Anvil 29(1): 4146.

Pienaar, M. 2002. Simultaneous interpreting services at South African provincial legislatures: a few cautionary notes. Southern African Linguistics and Applied Language Studies 22(4): 271-281.

Pöchhacker, F. and M. Schlesinger (ed.) 2002. The interpreting studies reader. London and New York: Routledge.

Roodt, H.C. 2001. Taalbeleid in Hoër Onderwys: veeltaligheid as vereiste van die grondwetlike en wetlike raamwerk. Aambeeld/Anvil 29(1): 15-20.

Roy, C.B. 2002. The problem with definitions, descriptions, and the role metaphors of interpreters. In F. Pöchhacker and M. Schlesinger (eds.) The interpreting studies reader. London and New York: Routledge.

Smit, F. 2001. Die demografie van taal in Suid-Afrika met spesiale verwysing na die onderrig- en wetenskaptaal aan universiteite. Aambeeld/Anvil 29(1): 21- 26.

Van Rensburg, F.I.J. 2001. Taal en universiteit. Aambeeld/Anvil 29 (1): 9-14. 
Van Rooy, B. 2005. The feasibility of simultaneous interpreting in university classrooms. Southern African Linguistics and Applied Language Studies 25(2): 81-90.

Wallmach, K. 2004. Seizing the surge of language by its soft, bare skull: the ideology of simultaneous interpreting in South Africa. Paper presented at the European Society for Translators Conference, Lisbon, 26-29 September 2004.

\section{Interviews}

Mr. Johan Blaauw: University of North-West (Potchefstroom campus), Private Bag X6001, Potchefstroom, 2520, South Africa

Prof. Thea de Wet: Dept. of Anthropology and Development Studies, University of Johannesburg, Auckland Park Campus, P.O. Box 524, Auckland Park, 2006, South Africa

Dr. Peter Ubombo-Jaswa: Dept. of Anthropology and Development Studies, University of Johannesburg, Auckland Park Campus, P.O. Box 524, Auckland Park, 2006, South Africa 